\title{
Oral and anal sex practices among high school youth in Addis Ababa, Ethiopia
}

Amsale Cherie $^{1 *}$ and Yemane Berhane ${ }^{2}$

\begin{abstract}
Background: Understanding the full range of sexual behaviors of young people is crucial in developing appropriate interventions to prevent and control sexually transmitted infections including HIV. However, such information is meager in developing countries. The objective of this study was to describe oral and anal sex practices and identify associated factors among high school youth.
\end{abstract}

Methods: A cross-sectional study was conducted among high school youth in Addis Ababa, Ethiopia. A multistage sampling procedure was followed to select a representative sample of school youth. The total sample size for this study was 3840. Data were collected using a self-administered questionnaire. Data analysis was guided by the ecological framework.

Results: The overall proportion of people who reported ever having oral sex was 5.4\% (190) and that of anal sex was $4.3 \%$ (154). Of these $51.6 \%$ (98) had oral sex and $57.1 \%$ (87) had anal sex in the past 12 months. Multiple partnerships were reported by $61.2 \%$ of the respondents who had oral sex and $51.1 \%$ of students practicing anal sex. Consistent condom use was reported by $12.2 \%$ of those practicing oral sex and $26.1 \%$ of anal sex. Reasons for oral and anal sex included prevention of pregnancy, preserving virginity, and reduction of HIV and STIS transmission. Oral sex practice was strongly and significantly associated with perception of best friends engagement in oral sex ( $A O R=5.7 ; 95 \% \mathrm{Cl} 3.6-11.2)$ and having illiterate mothers ( $\mathrm{AOR}=11.5 ; 95 \% \mathrm{Cl} 6.4-18.5)$. Similarly, anal sex practice was strongly and significantly associated with favorable attitude towards anal sex (AOR = 6.2; 95\% Cl 3.8-12.4), and perceived best friends engagement in anal sex ( $\mathrm{AOR}=9.7 ; 95 \% \mathrm{Cl}$ 5.4-17.7).

Conclusion: Considerable proportion of adolescents had engaged in oral and anal sex practices. Multiple sexual partnerships were common while consistent condom use was low. Sexual health education and behavior change communication strategies need to cover a full range of sexual practices.

Keywords: Youth, Sexual and reproductive health, Oral sex, Anal sex, HIV, STIs

\section{Background}

The sexual behavior of youth is a priority public health concern because of the high prevalence of HIV/AIDS and sexually transmitted infections (STIs) among this age group [1]. It is estimated that nearly $50 \%$ of the 35.3 million people who have been infected with the HIV virus acquired the infection before age 25 [2]. A total of 980,000 people were living with HIV/AIDS in Ethiopia in 2007 [3]. Each year an estimated 333 million new cases of curable STIs occurs worldwide [4-6].

\footnotetext{
* Correspondence: amsalec2002@yahoo.com

'School of Public Health, Addis Ababa University, P.O. Box: 33412, Addis Ababa, Ethiopia

Full list of author information is available at the end of the article
}

Abstinence, being faithful, and consistent condom use $(\mathrm{ABC})$ are the recommended prevention interventions. However, young people are still involved in early sexual practices, have multiple sexual partners and do not use condoms consistently [7-10].

Unprotected vaginal-penile intercourse has been known to be the predominant route for HIV and STIs transmission $[2-4,11]$. However, it is becoming evident that youth are involved in oral and anal intercourse [12-14]. Although the oral and anal sex behaviors of youth have been researched in the United States (US) for more than two decades [15-18], it was only recently that research evidences in some parts of Africa revealed the practice of oral and anal sex [19].

\section{Ciomed Central}


Studies in the US indicated that between $19.6 \%$ and $78 \%$ of young people had had oral sex in their life time and, of these only few youth used barrier protection against HIV and STIs [15-17]. In contrast a study conducted in Tanzania identified that $8.1 \%$ of young people were involved in oral sex [19]. Although there is a perception among youth that oral sex is risk free, evidence supports that several STIs, including chlamydia, human papillomavirus (HPV), gonorrhea, herpes, hepatitis, and HIV can be transmitted through oral sex $[20,21]$.

Unprotected anal intercourse carries the highest risk of HIV transmission as compared to oral and vaginal sex [22]. It was pointed out that between $3 \%$ and $41 \%$ of girls and between $7 \%$ and $20 \%$ of boys reported having engaged in anal sex $[23,24]$. It was identified that $5.0 \%$ of young people in Nigeria and $7.5 \%$ of students in Tanzania had anal intercourse $[19,25]$. The majority of students who reported having had anal sex had multiple sexual partners and most of them have not used condoms during anal intercourse [19,23-25].

Most studies and interventions related to youth sexual behavior focused on vaginal-penile intercourse. Also, sexual activity has been measured on the basis of whether young people have had vaginal intercourse or not [26]. Studies have identified that individual, family, and peer factors predict vaginal-penile intercourse among youth $[13,27,28]$. However, only few studies have assessed the relationship between these multilevel factors with oral and anal sex.

Although data on the proportion of young people engaged in forced oral and anal sex is lacking, available evidences on vaginal sex suggested that not all sexual experiences of young people are voluntary. Extant evidences indicated that coerced first sex among girls in Sub-Saharan Africa ranged from 32\% to 50\% [28]. Studies also shown that reported unwanted sex among males ranged from $2.5 \%$ to $42 \%$ among students in Nigeria $[29,30]$.

Studies on oral and anal sex practices and the associated factors among youth in Ethiopia are scarce. In addition, most studies use individual factors as a predictor to sexual behavior while the sexual behavior of young people is influenced by a multitude of factors. The ecological framework, however, looks into the individual, parental and peer influences on youth sexual behavior. Therefore, understanding the determinants of oral and anal sex using the ecological framework is crucial. Thus, it was the purpose of this study to describe oral and anal sex practices and identify associated factors among high school youth. In effect, this research provides the basis for the designing and implementation of effective preventive interventions that seek to minimize sexual risk behavior and, thereby reducing the incidence of HIV and STIs. This research also seeks to inform clinical practice, education and counseling guidelines.

\section{Methods}

This is a cross sectional study conducted among regularly attending high school youth in Addis Ababa, Ethiopia.

Addis Ababa is the capital city of Ethiopia and has an estimated 3 million population. The youth population (15-24 year) constitutes about $20 \%$ of the total city population [31]. There were 70 secondary schools in the city ( 21 Government, 43 private and 6 foreign community schools) at the time of the study. The total number of high school students in the academic year 2008/2009 was 96571 . Of this, 84352 students were attending Government high schools. About $49.0 \%$ of the Government and $55.4 \%$ of the Non -government school students were females [32].

All high schools primarily established to enroll Ethiopian students in the city of Addis Ababa and students whose age was 15-24 years were included in the study. However, students who were not able to complete the questionnaire without assistance such as the visually impaired were excluded.

The study population was selected from the source population using three-stage sampling. Addis Ababa is administratively divided into 10 Sub Cities. In the first step one high school was selected randomly from each sub-city. The sample size for each selected school was assigned proportionate to the total student population. Then, in the selected schools, from each grade, one section was selected by lottery method. Students from the identified section were selected using a systematic sampling method. The starting number was randomly chosen from the first three in the section roll call. Every third student was then taken until the assigned number was reached.

This study is part of a PhD project. Therefore, the sample size was calculated for the whole dissertation based on level of significance of $95 \%$, power $80 \%$, since the sample selection passed through three stages a design effect of 3 , and proportion of condom use among adolescents $50.7 \%$. In addition, $20 \%$ allowance was considered for non-response based on the findings from previous school based studies [7]. Based on these the required sample size was found to be 3840 students.

The survey was a paper-and-pencil self-administered questionnaire. The questionnaire was prepared in English and translated into Amharic (the Ethiopian national language). The Amharic questionnaire was pre-tested in schools not selected for the study. Two supervisors with master of public health and ten nurses facilitated the data collection. The research team was trained for 2 days to help them understand the purpose of the study 
and familiarize themselves with the questions so that they can explain to students, if asked. Data collection in all schools was completed within 1 week to minimize information contamination. The Principal Investigator made both scheduled and unscheduled (surprise) supervisory visits during the data collection. Before commencing the study, official contact with concerned personnel of the City Education Bureau, Zonal Education Bureau, directors of the selected schools and guidance of each school were made by the Principal Investigator. Refreshments were provided for all participants.

The study included items dealing with the dependent variable oral and anal sexual behavior of students and potential independent factors at the individual, family, and peer level factors identified from previous studies $[26,27,33,34]$. The individual level factors included sex, age, self-esteem, attitude about sex, and educational aspirations. Family factors consisted of parental education level and family structure. Peer level factors comprised of perceived oral and anal sexual experience of the participant's best friends.

To assess the oral and anal sexual activity of students all participants were asked whether they ever had oral or anal sexual intercourse in their lifetime. Yes and no responses were available to be circled by the respondents. Oral sex was defined as "when some-one puts his or her mouth on their partner's penis or vagina or lets their partner put his or her mouth on their penis or vagina". Anal sex means when a man puts his penis in his partner's anus or when one lets their partner insert the penis in their anus".

Self-esteem was measured by Rosenberg's self-esteem scale [35].The scale consisted of ten questions answered on a four point scale-from strongly agree to strongly disagree. Attitude about sex was assessed through two items which asked, how do you feel about teenagers having oral sex and, how do you feel about teenagers having anal sex?" Responses included 1 = Favorable and $2=$ Unfavorable.

Data coding, entry, and cleaning was processed using EPI info version 6.4 and the analysis was made using SPSS version 15 statistical package. Analysis was guided by the ecologi cal framework. The coding of open ended questions was made by two persons. Each coder categorized the responses in the same way. Logistic regression models were used to see the association of oral and anal sex and independent variables at the individual, familial, and extra-familial levels. Variables were entered into three blocks. Block 1 contained the individual level variables (sex, age, self-esteem, attitude, and college aspiration). Family structure and parental education were entered next in Block 2. At the extra-familial level (Block 3), peer sexual activity was entered. The three regression models were significant at each of the three levels. The predictors in model 1 accounted for $46 \%$ of the variance in sexual activity when variables in model 2 were entered the model's explanatory power slightly increased to $50 \%$ of the variance and when model 3 variables were included the explanatory power of the model considerably improved and increased to 56\%.

Ethical clearance was secured from the Addis Ababa University, School of Public Health and IRB of the Faculty of Medicine. Persons between 15 and 18 years in Ethiopia are regarded 'Consenting Minors' and can be interviewed without parental consent. Verbal informed consent was obtained from each respondent after explaining the purpose of the study. Participants were assured that participation is voluntary, the information they provide will be kept completely anonymous and confidential. Students were also informed the possibility of opting out at any time if they feel to do so.

\section{Results}

A total of 3840 in school youth aged 15-24 were identified from 10 high schools. Of these $92.5 \%$ (3543) of students fully responded to the self administered questionnaire. There was no refusal, but 7.7\% (297) of participants responded to less than a quarter of the questions. Thus, their responses were not included in the analysis.

\section{Socio-demographic characteristics of the study population}

The Socio-demographic characteristics of the respondents are depicted in Table 1 . From the 3543 respondents, $50.5 \%$ (1789) were females and $22.5 \%$ (796) were between the age group 15 and 16 years. The mean age of the study population was 17.6 years $(\mathrm{SD}=1.5)$. Over all 55.4\% (1964) of the respondents live with both parents. Regarding parental education $17.0 \%$ (602) and $26.2 \%$ (928) of the respondents' fathers and mothers were without formal education, respectively.

The reported oral sex practices of high school students are shown in Table 2. The overall proportion of those who reported ever having oral sex was 5.3\% (190). Of which $13.2 \%$ (25) initiated oral sex before the age of 10 and $44.2 \%$ (84) had the first oral sex without their consent. The mean age at first oral sex among the study population was 14.6 years $(\mathrm{SD}=2.1)$. Among ever had oral sex; $51.6 \%$ (98) of the respondents had reported oral sex in the 12 months preceding the survey. Of these $61.2 \%(60)$ had more than one oral sex partners, $48.0 \%$ (47) received gift for the exchange of oral sex, only $12.2 \%$ (12) of them used condom every time they had oral sex, and $80.6 \%(79)$ of students had intention to continue having oral sex in the future.

Table 3 depicts the anal sex practices of respondents. Overall 4.3\% (154) of respondents reported ever having 
Table 1 Socio-demographic Characteristics of 3543 High School Students.

\begin{tabular}{ll}
\hline Characteristics & Number (\%) \\
\hline Sex & \\
\hline Male & $1789(50.5)$ \\
\hline Age group (mean $=\mathbf{1 7 . 6}, \mathbf{S D}=\mathbf{1 . 5}$ years) & $1754(48.5)$ \\
\hline Young adolescents (15-16) & $796(22.5)$ \\
\hline Older adolescents (17-24) & $2747(77.5)$ \\
\hline School Grade & \\
\hline Ninth & $701(19.8)$ \\
\hline Tenth & $703(20.3)$ \\
\hline Preparatory I & $770(21.7)$ \\
\hline Prep II & $670(18.9)$ \\
\hline Vocational & $699(19.7)$ \\
\hline Living arrangement & $1964(55.4)$ \\
\hline Both Parents & $1579(44.6)$ \\
\hline Other arrangements* & \\
\hline Paternal literacy & $602(17.0)$ \\
\hline Illiterate and Non formal & $2941(83.0)$ \\
\hline Formal school & $928(26.2)$ \\
\hline Maternal literacy & $2615(73.8)$ \\
\hline Illiterate and Non formal &
\end{tabular}

Addis Ababa, Ethiopia April, 2009

* Include all not living with both parent

Table 2 Oral sexual practices among 3543 high School students in Addis Ababa, Ethiopia

\begin{tabular}{ll}
\hline Practices & $\begin{array}{l}\text { Number } \\
(\%)\end{array}$ \\
\hline Reporting ever having oral sex & $190(5.4)$ \\
\hline Age at first oral sex (mean $=14.6, \mathbf{S D}=\mathbf{2 . 1})$ & $25(13.2)$ \\
\hline Below 10 years & $103(54.2)$ \\
\hline $11-15$ years & $62(32.6)$ \\
\hline 16-20 years & $84(44.2)$ \\
\hline Reporting forced first oral sex & $98(51.6)$ \\
\hline Reporting having oral sex (in the past 12 months) & $38(38.8)$ \\
\hline Number of oral sex partners (in the past 12 months) & $35(35.7)$ \\
\hline One & $25(25.5)$ \\
\hline 2-4 & $12(12.2)$ \\
\hline More than four & $41(41.8)$ \\
\hline Condom use during oral sex (in the past 12 months) & $45(45.9)$ \\
\hline Every time & $47(48.0)$ \\
\hline Sometime & $79(80.6)$ \\
\hline Never & \\
\hline Received money/gift in exchange for oral sex (past 12 \\
months)
\end{tabular}

Table 3 Anal sexual practices among 3543 high School students in Addis Ababa, Ethiopia

\begin{tabular}{ll}
\hline Practices & $\begin{array}{l}\text { Number } \\
(\%)\end{array}$ \\
\hline Reporting ever having anal sex & $154(4.3)$ \\
\hline Age at first anal sex (mean $=14.8$, SD $=$ 1.7) & $30(19.5)$ \\
\hline Below 10 years & $65(42.2)$ \\
\hline $11-15$ years & $59(38.3)$ \\
\hline 16-20 years & $68(44.2)$ \\
\hline Reporting forced first anal sex & $88(57.1)$ \\
\hline Reporting having anal sex (in the past 12 months) & $43(48.9)$ \\
\hline Number of anal sex partners (in the past 12 months) & $27(30.7)$ \\
\hline One & $18(20.5)$ \\
\hline 2-4 & $23(26.1)$ \\
\hline More than four & $31(35.2)$ \\
\hline Condom use during anal sex (in the past 12 months) & $34(38.6)$ \\
\hline Every time & $46(52.3)$ \\
\hline Sometime & $63(82.9)$ \\
\hline Never & \\
\hline Received money/gift in exchange for anal sex (past 12 \\
months)
\end{tabular}

anal sex. Of these $19.5 \%$ (30) had their first anal sex before the age of 10 and for the $44.2 \%$ (68) the first anal sex was not consensual. The mean age at first anal sex among the study population was 14.8 years $(\mathrm{SD}=1.7)$. About $57.1 \%$ (87) of the students reported having anal sex in the last 12 months. Of these only $26.1 \%$ (23) used condom consistently during anal sex, and $51.1 \%$ (45) of the students reported having more than one anal sex partners, $52.3 \%$ (46) had received gift for the exchange of anal sex, and $82.9 \%$ (63) of respondents intend to continue having anal intercourse in the future.

The main reasons given by the respondents for practicing oral sex were preventing pregnancy 95.9\% (142), minimizing risk of HIV acquisition 86.5\% (128), preserving virginity $85.8 \%$ (127), and reducing the risk of STIs transmission $80.4 \%$ (119). (See Figure 1).

The predominant reasons reported by the respondents for practicing anal sex were minimizing the risk of pregnancy $92.1 \%$ (70), preserving virginity $85.5 \%$ (65), minimizing the risk of STIs $82.9 \%$ (63), and minimizing the risk of HIV transmission 77.6\% (59). (See Figure 1).

Oral sex practice was significantly associated with younger age group (AOR $=3.2 ; 95 \% \mathrm{CI}$ : 1.9-5.3), being female $(\mathrm{AOR}=1.3$; $95 \% \mathrm{CI} 1.1-2.2)$, having positive attitude about oral sex $(\mathrm{AOR}=2.3 ; 95 \% \mathrm{CI} 1.7-4.5)$, having low aspirations for college $(\mathrm{AOR}=3.1 ; 95 \% \mathrm{CI} 2.8-5.9)$, and having low self-esteem $(\mathrm{AOR}=2.1 ; 95 \% \mathrm{CI} 1.7-3.9)$. (See Table 4). 


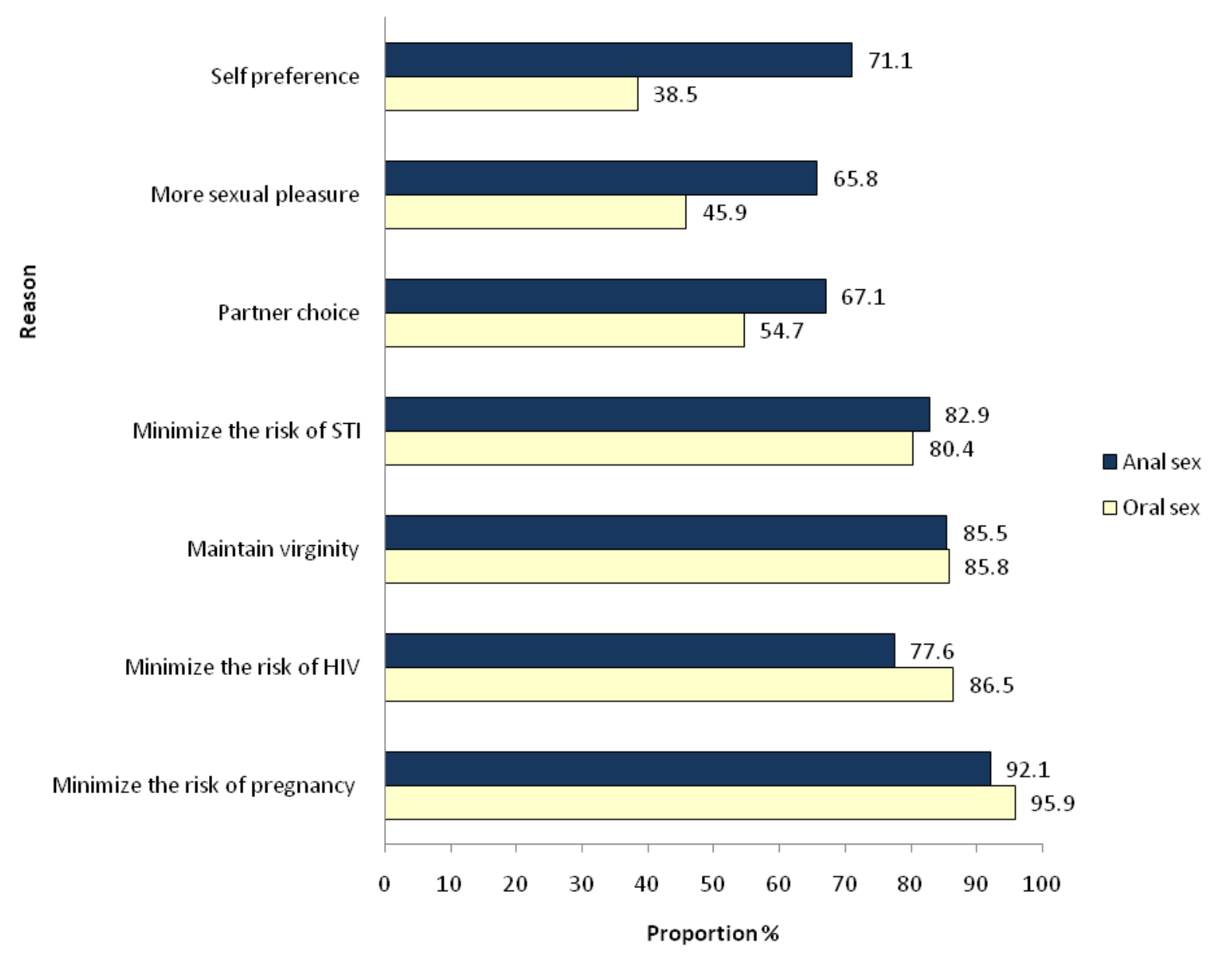

Figure 1 Reasons for oral and anal sex preference among youth, Addis Ababa, Ethiopia.

Anal sex was significantly associated with younger age $(\mathrm{AOR}=1.7 ; 95 \% \mathrm{CI}: 1.3-3.1)$, being male $(\mathrm{AOR}=2.9$; 95\%CI 1.6-4.7), having positive attitude towards anal sex $(\mathrm{AOR}=6.2$; 95\%CI 3.8-12.4), having low college aspirations $(\mathrm{AOR}=4.2 ; 95 \% \mathrm{CI} 2.8-8.1$ ), and having low selfesteem $(\mathrm{AOR}=1.6$; 95\%CI 1.2-3.1). (See Table 5).

The study also looked into familial factors that might be associated with anal and oral sex practices. Oral sex practice was less likely among students living with both parents $(\mathrm{AOR}=0.4 ; 95 \% \mathrm{CI} 0.2-0.9)$. On the other hand students having illiterate mothers were more likely to be involved in oral sex $(\mathrm{AOR}=11.5 ; 95 \% \mathrm{CI}$ 6.4-18.5). (See Table 4). Likewise, students living with both parents were less likely to have anal sex $(\mathrm{AOR}=0.4$; 95\%CI 0.2 $0.9)$; and students having illiterate mothers were more likely to engage in anal sex $(\mathrm{AOR}=11.6$; 95\%CI 7.8 19.6). Students whose fathers are illiterate were more likely to have anal sex than their counterparts (AOR = 7.8; 95\%CI 5.3-14.9) (See Table 5).

Among peer level factors, perception of involvement of best friends in oral sex was significantly associated with oral sex practice $(A O R=5.7 ; 95 \% C I$ 3.6-11.2). (See Table 4). Similarly, students who perceived their best friends are engaged in anal sex were more likely to have anal sexual activity $(\mathrm{AOR}=9.7 ; 95 \%$ CI 5.4-17.7). (See Table 5).

\section{Discussion}

In this study the proportion of school youth engaged in oral and anal sex is considerable about 1 in 20 youth were involved in oral and anal sex practices. Moreover, a large proportion of youths involved in oral and anal sex were not taking appropriate protection measures such as consistent condom use. Reasons mentioned for having oral and anal sex included preventing pregnancy, preserving virginity, and reducing HIV and STIs transmission risks. All individual, parental, and peer level factors were associated with involvement in oral and anal sex.

Previous studies reported a wide ranging oral sex $(19.6 \%-78 \%)$ and anal sex (5\%-54\%) practices $[12,16,17,19]$. Although the proportion of oral and anal sex in this study appears to be low, the proportion of 
Table 4 Independent correlates of oral sex among 3543 high school students in Addis Ababa, Ethiopia, 2009

\begin{tabular}{|c|c|c|c|}
\hline Sources of effect & $\begin{array}{l}\text { Number (\%) } \\
\text { Practicing oral sex }\end{array}$ & $\begin{array}{l}\text { Unadjusted OR } \\
(95 \% \mathrm{Cl})\end{array}$ & $\begin{array}{l}\text { Adjusted } \\
\text { OR }(95 \% \mathrm{Cl})\end{array}$ \\
\hline \multicolumn{4}{|l|}{ Age } \\
\hline $15-16$ & 79(41.6) & $2.6(1.9,3.6)$ & $3.2(1.9-, 5.3)$ \\
\hline 17 and above & $111(58.4)$ & Reference & Reference \\
\hline \multicolumn{4}{|l|}{ Sex } \\
\hline Female & $101(53.2)$ & $1.1(0.8,1.5)$ & $1.3(1.1-, 2.2)$ \\
\hline Male & $89(46.8)$ & Reference & Reference \\
\hline \multicolumn{4}{|l|}{ Attitude } \\
\hline Positive feeling & $52(27.4)$ & $1.3(1.1,1.7)$ & $2.3(1.7-, 4.5)$ \\
\hline Negative feeling & 138(72.6) & Reference & Reference \\
\hline \multicolumn{4}{|l|}{ College Aspiration } \\
\hline Low & $121(63.7)$ & $3.6(2.1,4.8)$ & $3.1(2.8-, 5.9)$ \\
\hline High & 69(36.3) & Reference & Reference \\
\hline \multicolumn{4}{|l|}{ Self esteem } \\
\hline Low & $118(62.1)$ & $1.8(1.2,3.4)$ & $2.1(1.7-, 3.9)$ \\
\hline High & 72(37.9) & Reference & Reference \\
\hline \multicolumn{4}{|l|}{ Living arrangement } \\
\hline Both parents & 78(41.1) & $0.5(0.2,0.7)$ & $0.4(0.2-, 0.9)$ \\
\hline Other living arrangements & 112(58.9) & Reference & Reference \\
\hline \multicolumn{4}{|l|}{ Maternal education } \\
\hline Illiterate & 152(80.0) & 13.2(9.4, 17.6) & $11.5(6.4-, 18.5)$ \\
\hline Literate & $38(20.0)$ & Reference & Reference \\
\hline \multicolumn{4}{|l|}{ Paternal education } \\
\hline Illiterate & $47(24.7)$ & $1.6(1.2,2.9)$ & $1.4(0.9-, 3.2)$ \\
\hline Literate & 143(75.3) & Reference & Reference \\
\hline \multicolumn{4}{|c|}{ Perception of peer oral sexual activity } \\
\hline Yes & 98(51.6) & $4.6(2.8,7.9)$ & $5.7(3.6-, 11.2)$ \\
\hline No & $92(48.4)$ & Reference & Reference \\
\hline
\end{tabular}

youth engaged in multiple sexual partnerships, and the extremely low and inconsistent use of condom during such sexual encounters is a major concern. In addition, approximately 3 quarters of sexually active students in this study intend to continue having oral and anal sex in the next 6 months. This is higher than the reported $31.5 \%$ oral sex intention from America [15]. This speaks that oral and anal sexual activity among some young people is a planned experience. However, the motives behind this intention need further scrutiny. Nearly half of the currently sexually active students received gift at the exchange of oral and anal sex. Young people engaged in transactional oral and anal sex are at high risk for STIs including HIV, because they may be less able to negotiate and make decision about the timing and conditions of sex with their partners [36]. Therefore, sexual health educations need to be given about the dangers of oral and anal sex and the ways on how to protect themselves from STIs including HIV.
The results of this study highlight several key issues that merit further consideration by practitioners, teachers, parents, the community and peer educators. Since youth sexual behavior is interrelated, intertwined and influenced by a multitude of factors, intervention should target the individual, family and peer determinants rather than focusing on isolated individual behaviors.

Studies on individual level predictors of oral and anal sex are scarce. However, extant literatures on vaginal sex reported association of individual level variables such as self-esteem, college aspiration and attitude towards sex with engagement in vaginal intercourse [37-40]. Similar findings were found in this study. Low self esteem, favorable attitude towards oral and anal sex and low college aspiration were associated with involvement in oral and anal sex. This finding underscores that parents and schools should inculcate the value of education in children starting from childhood. Interventions to garner and raise the self esteem of young people as 
Table 5 Independent correlates of anal sex among 3543 high school students in Addis Ababa, Ethiopia, 2009

\begin{tabular}{|c|c|c|c|}
\hline Sources of effect & $\begin{array}{l}\text { Number (\%) } \\
\text { Practicing anal sex }\end{array}$ & $\begin{array}{l}\text { Unadjusted OR } \\
(95 \% \mathrm{Cl})\end{array}$ & $\begin{array}{l}\text { Adjusted } \\
\text { OR }(95 \% \mathrm{Cl})\end{array}$ \\
\hline \multicolumn{4}{|l|}{ Age } \\
\hline $15-16$ & $53(34.4)$ & $1.8(1.3,2.5)$ & $1.7(1.3-, 3.1)$ \\
\hline 17 and above & $101(65.6)$ & Reference & Reference \\
\hline \multicolumn{4}{|l|}{ Sex } \\
\hline Female & $114(74.0)$ & $3.03(1.2,5.8)$ & $2.9(1.6-, 4.7)$ \\
\hline Male & $40(26.0)$ & Reference & Reference \\
\hline \multicolumn{4}{|l|}{ Attitude } \\
\hline Positive feeling & $69(44.8)$ & $6.1(3.4,10.7)$ & $6.2(3.8-, 12.4)$ \\
\hline Negative feeling & $85(55.2)$ & Reference & Reference \\
\hline \multicolumn{4}{|l|}{ College Aspiration } \\
\hline Low & $106(68.8)$ & $4.4(2.2,8.6)$ & $4.2(2.8-, 8.1)$ \\
\hline High & $48(31.2)$ & Reference & Reference \\
\hline \multicolumn{4}{|l|}{ Self esteem } \\
\hline Low & $87(56.5)$ & $1.5(1.1,2.9)$ & $1.6(1.2-, 3.1)$ \\
\hline High & $67(43.5)$ & Reference & Reference \\
\hline \multicolumn{4}{|l|}{ Living arrangement } \\
\hline Both parents & $57(37.0)$ & $0.5(0.1,0.8)$ & $0.4(0.2-, 0.9)$ \\
\hline Other living arrangements & $97(63.0)$ & Reference & Reference \\
\hline \multicolumn{4}{|l|}{ Maternal education } \\
\hline Illiterate & $121(78.6)$ & $11.7(5.3,18.9)$ & 11.6(7.8-, 19.6) \\
\hline Literate & $33(21.4)$ & Reference & Reference \\
\hline \multicolumn{4}{|l|}{ Paternal education } \\
\hline Illiterate & $93(60.4)$ & $8.6(4.8,12.1)$ & 7.8(5.3-, 14.9) \\
\hline Literate & 61(39.6) & Reference & Reference \\
\hline \multicolumn{4}{|c|}{ Perception of peer oral sexual activity } \\
\hline Yes & 105(68.2) & $9.6(4.8,13.2)$ & $9.7(5.4-, 17.7)$ \\
\hline No & 49(31.8) & Reference & Reference \\
\hline
\end{tabular}

well as changing attitudes towards safe sex should be in place.

Living with both parents was protective from oral and anal sex. This concurs with the results of previous findings [19]. The possible explanation for this is families headed by two parents may have more time to supervise their children and might be physically and emotionally available to communicate about sexuality to their children than other family constellations. Therefore, marriage counseling and interventions targeting family life should be given consideration. Furthermore, maternal education was a strong predictor of oral and anal sexual intercourse. As a result, female education should be given sufficient consideration.

Consistent with other studies, best friend's sexual activity was a strong predictor for engagement in oral and anal sexual activity in this study $[27,41]$. Peers are main sources of information and influence related to reproductive and sexuality issues to young people [41].
As a result, correct, incorrect, safe, or risky information can be introduced, circulated and diffused among members of this social system. Thus, strengthening school peer education programme is a worthy investment to educate students about the risks associated with oral and anal sex and available protective measures.

Corroborating with previous research findings, the majority of the youth engaged in oral and anal sex wrongly perceived that these sexual acts provide protection from STIs including HIV [13,15]. This is alarming and has serious programmatic and policy implications. Unless measures are taken to change this misperception, oral and anal sex could become the source for the next wave of HIV and STIs epidemic. Therefore, the inclusion of relevant information on sexual matters and prevention of STIs in the school curriculum is essential. The majority of the youth practicing anal and oral sex also consider these modes as means of preventing pregnancy. Although that might be true, these acts do not 
protect against the risk of contracting STIs including HIV. Therefore, students need to be advised on safer sexual practices. Furthermore, it is vital that schools sexual health education be comprehensive enough to cover the wider sexual experiences and educate students about the risks associated with oral and anal sex.

Approximately one in seven of the sexually active student's oral sexual debut and one in five respondent's first anal intercourse in this sample occurred before the age of 10. In addition, nearly half of oral and anal sex debut of students happened without their consent. This is higher than the results of studies in different parts of Africa [42-45]. Although coerced sex may occur at any age, engagement in forced oral and anal sex at an early age, where these children are not capable to defend and protect themselves is catastrophic. Child sexual abuse is against human rights and has physical, psychological, and social consequences as well as negative impact on the education and future survival and hope of children [46]. Thus, the prevention of child sexual abuse needs investment from government, health sector, legal, education, police, the community, and the family. Prevention through public education and school health education; early detection and treatment of victims should be in place.

The major limitation of this study is the accuracy of self reported oral and anal sexual practices of respondents. As these sexual practices are considered taboo in Ethiopia there may be social desirability bias leading to under reporting. However, attempts were made to minimize this bias by using self-administered anonymous questionnaire and ensuring privacy during data collection. Despite this limitation, the large sample size and the representativeness of the sample make the findings of this study generalizable to similar population in large urban cities in Ethiopia.

\section{Conclusion}

The findings of this study indicated that a negligible number of students initiated oral and anal sex without their consent before their teen years. Students engaged in multiple partners' oral and anal sexual relationships without proper protection, and received gift for the exchange of oral and anal sex. The majority of whom who had oral and anal sex had future intention to have oral and anal sex in the next 6 months. The main reasons for involvement in oral and anal sex were prevention of pregnancy, minimize the risk of HIV, preserving virginity and reduction of STIs transmission. Favorable attitude about oral and anal sex, low college aspirations and low self esteem were individual level predictors of oral and anal sex. Living with both parents and maternal literacy were protective from oral and anal sex. Students who perceive their best friends engage in oral and anal sex were highly likely to involve in oral and anal sexual activity.

Therefore, future interventions should target the multilevel adolescent's sexual behavior and influences at individual, parental and peer levels. Interventions that aim to illuminate educational aspirations raise the self esteem of young people, and change attitudes towards safe sex practices should be in place. School sexual health education should cover the wider sexual experience and educate students about the risks associated with oral and anal sex and its prevention mechanisms. Further in-depth exploration is needed to explain the motivation behind oral and anal sex.

\section{Acknowledgements}

We want to express our heartfelt thanks to John Hopkins University for funding the study through the School of Public Health of Addis Ababa University. Authors would also greatly appreciate the study participants for their willingness to share their ideas and thoughts. The City Education Office and the officials of the study schools are acknowledged for their support during the conduct of the study.

\section{Author details}

${ }^{1}$ School of Public Health, Addis Ababa University, P.O. Box: 33412, Addis Ababa, Ethiopia. ${ }^{2}$ Addis Continental Institute of Public Health, P.O. Box: 26751/1000, Addis Ababa, Ethiopia.

\section{Authors' contributions}

Both authors participated from the inception of the research idea to proposal development, data collection, analysis and preparation of the manuscript. All authors have read and approved the final manuscript.

\section{Competing interests}

The authors declare that they have no competing interests.

Received: 8 August 2011 Accepted: 4 January 2012

Published: 4 January 2012

\section{References}

1. CDC: Youth Risk Behavior Surveillance-United States, 2009. MMWR 2010, 59(SS-5):1-142.

2. Joint United Nations on HIV/AIDS (UNAIDS): AIDS epidemic update. 2010.

3. Federal Democratic Republic of Ethiopia: Federal HIV/AIDS Prevention and Control Office: Report on progress towards implementation of the UN Declaration of Commitment on HIV/AIDS. 2010.

4. WHO: Global prevalence and incidence of selected curable sexually transmitted diseases: overview and estimates..

5. CDC, Sexually Transmitted Disease Surveillance Report 2007.

6. Forhan SE, et al: Prevalence of sexually transmitted infections among female adolescents aged 14 to 19 in the United States. Pediatrics 2009, 124:1505.

7. Cherie A, Mitkie G, Ismail S, Berhane Y: Perceived sufficiency and usefulness of IEC materials and methods. Afr J Reproductive Health 2005, 9(1).

8. Barnett T, Parkhurst J: "HIV/AIDS: sex, abstinence, and behavior change DOI:dx.doi.org". The Lancet Infectious Diseases 2005, 5(9):590-593.

9. Murphy EM, Greene ME, Mihailovic A, Olupot-Olupot P: "Was the "ABC" Approach (abstinence, being faithful, using condoms) responsible for Uganda's Decline in HIV?". PLoS Med 2006, 3-9, e379.

10. Lillie TL, Curbow B: Kenyan in-School Youths' level of understanding of abstinence, being faithful and consistent condom use terms: implications for HIV-prevention programs. Journal of Health Communication 2009, 14:276-292.

11. Ministry of Health, Ethiopia: Disease prevention and control department. AIDS IN Ethiopia; 2006. 
12. Markham CM, Peskin MF, Addy RC, Baumer ER, Tortolero SR: Patterns of vaginal, oral, and anal sexual intercourse in an urban seventh-grade population. J Sch Health 2009, 79:193-200.

13. Prinstein MJ, Meade CS, Cohen GL: Adolescent oral sex, peer popularity, and perceptions of best friends' sexual behavior. J Pediatr Psychol 2003, 28(4):243-249.

14. Brady SS, Halpern-Felsher BL: Adolescents' reported consequences of having oral sex versus vaginal sex. Pediatrics 2007, 119(2):229-236.

15. Halpern-Felsher BL, Cornell JL, Kropp RY, Tschann JM: Oral versus vaginal sex among adolescents: perceptions, attitudes, and behavior. Pediatrics 2005, 115(4):845-851, [Pub Med].

16. Lindberg LD, Jones R, Santelli JS: Non-coital sexual activities among adolescents. J Adolesc Health 2008, 43(3):231-238, [Pub Med].

17. Ompad DC, et al: Predictors of early initiation of vaginal and oral sex among urban young adults in Baltimore, Maryland. Arch Sex Behav 2006, 35(1):53-65

18. Smith EA, Udry JR: Coital and non-coital sexual behaviors of white and black adolescents. Am J Public Health 1985, 75:1200-1203.

19. Kazaura MR, Masatu MC: Sexual practices among unmarried adolescents in Tanzania. BMC Public Health 2009, 9:373.

20. Hawkins DA: Oral sex and HIV transmission. Sexually Transmitted Infections 2001, 77:307-308.

21. Centers for Disease Control: Preventing the sexual transmission of HIV, the virus that causes AIDS: What you should know about oral sex. 2000, Retrieved January 3, 2005, from http://www.cdc.gov/hiv/pubs/Facts/oralsex. pdf.

22. Joseph A, James $H$, Molly M, Britney W: Midwestern rural adolescents' anal intercourse experience. J Rural Health 2010, 00:1-9.

23. Houston AM, Fang J, Husman D, Peralta L: More than just vaginal intercourse: anal intercourse and condom use patterns in the context of "main" and "casual" sexual relationships among urban minority adolescent females. J Pediatr Adolesc Gynecol 2007, 20:299-304.

24. Lescano CM, Houck CD, Brown LK, et al: Project SHIELD Study Group. Correlate of heterosexual anal intercourse among at-risk adolescents and young adults. Am J Public Health 2009, 99:1131-1136.

25. Adenike I, Bello W, Olugbenga L: Sexual risk behavior among in-school adolescents in public secondary schools in a Southwestern City in Nigeria. Int J Health Res 2009, 2(3):243-251.

26. Bersamin MM, Walker S, Fisher DA, Grube JW: Correlates of oral sex and vaginal intercourse in early and middle adolescence. J Res Adolesc 2006, 16:59-68.

27. Kotchick BA, Shaffer A, Forehand R, Miller KS: Adolescent sexual risk behavior: a multi-system perspective. Clin Psychology Rev 2001, 21(4):493-519, [Pub Med].

28. Ann M, Kofi A, Nyovani M, Johannes J, Akwasi K: Coerced first sex among adolescent girls in sub-saharan africa: prevalence and context. Afr J Reprod Health 2007, 11(3):62-82.

29. Ajuwon Ademola J, et al: Experience of sexual coercion among adolescents in Ibadan, Nigeria. Afr J Reproductive Health 2001, 5(3):120-131.

30. Slap G, et al: Sexual behavior of adolescents in Nigeria: cross sectional survey of secondary school students. Br Med J 2003, 326:15-18.

31. The 1994 population and housing census of Ethiopia. Result for Addis Ababa: Volume 1. Statistical reports 1995.

32. Addis Ababa City Administration Education Bureau. Annual educational booklet 2008.

33. Corcoran J: 'Ecological factors associated with adolescent sexual activity. Social Work in Health Care 2000, 30:4, 93-111.

34. Buhi ER, Goodson P: Predictors of adolescent sexual behavior and intention: a theory-guided systematic review. J Adolescent Health 2007, 40:4-21.

35. Rosenberg M: conceiving the self New York: Basic Books; 1979.

36. Gregson S, Nyamukapa CA, Garnett GP, Mason PR, Zhuwau T, Carael M, Chandiwana SK, Anderson RM: "Sexual mixing patterns and sexdifferentials in teenage exposure to HIV infection in rural Zimbabwe.". The Lancet 2002, 359:1896-1903.

37. Spencer JM, Zimet GD, Aalsma MC, Orr DP: Self-esteem as a predictor of initiation of coitus in early adolescents. Pediatrics 2002, 109:581-585.

38. White RT: Reconceptualizing HIV infection among poor black adolescent females: an urban poverty paradigm. Health Promotion Prac 2002, 3(2):302-312.
39. Kirby D: Effective approaches to reducing adolescent unprotected sex, pregnancy, and childbearing. J Sex Res 2002, 39(1):p51-58.

40. Kirby D: Reflections on two decades of research on teen sexual behavior and pregnancy. J School Health 1999, 69(3):89.

41. Kinsman S, Romer D, Frank F, Schwarz D: Early Sexual initiation: the role of peer norms. Pediatrics 2002, 102(5):1185-1192.

42. Wood K, Lambert $H$, Jewkes R: "Showing roughness in a beautiful way": talk about love, coercion, and rape in South African youth sexual culture. Med Anthropol Q 2007, 21:277-300.

43. Erulkar AS: The experience of sexual coercion among young people in Kenya. Int Fam Plan Perspect 2004, 30:182-9.

44. Koenig MA, Zablotska I, Lutalo T, Nalugoda F, Wagman J, Gray R: Coerced first intercourse and reproductive health among adolescent women in Rakai, Uganda. Int Fam Plan Perspect 2004, 30:156-63.

45. Ajuwon AJ, Olley BO, Akin-Jimoh I, Akintola O: Experience of sexual coercion among adolescents in Ibadan, Nigeria. Afr J Reprod Health 2001, 5:120-31.

46. World Health Organization: World Report on Violence and Health Geneva, Switzerland: World Health Organization; 2002.

\section{Pre-publication history}

The pre-publication history for this paper can be accessed here:

http://www.biomedcentral.com/1471-2458/12/5/prepub

doi:10.1186/1471-2458-12-5

Cite this article as: Cherie and Berhane: Oral and anal sex practices among high school youth in Addis Ababa, Ethiopia. BMC Public Health 2012 12:5.

\section{Submit your next manuscript to BioMed Central and take full advantage of:}

- Convenient online submission

- Thorough peer review

- No space constraints or color figure charges

- Immediate publication on acceptance

- Inclusion in PubMed, CAS, Scopus and Google Scholar

- Research which is freely available for redistribution

Submit your manuscript at www.biomedcentral.com/submit
C) Biomed Central 